This is a pre-print of a chapter that will appear in the book Workplace Culture in Academic Libraries: The Early 21st Century edited by Kelly Blessinger and Paul Hrycaj (2012). Please refer to the completed book for full bibliographic information.

\title{
Building Staff Morale and Creating a Positive Workplace
}

\section{Eric Jennings and Kathryn Tvaruzka}

Libraries often have arbitrary divisions among staff members - librarians vs. paraprofessionals, technical services vs. public services, staff vs. students, etc. The University of Wisconsin-Eau Claire's McIntyre Library has broken down many of these divisions through a variety of internal and external activities; some officially work-related and others just for fun and recreation. Through these team-based activities staff morale has improved. This chapter will showcase some of the activities and projects done at McIntyre Library and discuss the positive outcomes these have had on library employees.

Divisions between staff members are not unique to libraries. Whether the divisions are based on gender, age, education, or other personality and social characteristics, it is something that is unavoidable. Library staff members are also divided by department, division, floor, status, and seniority. Overcoming differences between individuals and groups within a workplace is no easy task, but doing so has a direct impact on the quality of services offered at the library. Infusing playfulness and fun into the workplace tends to increase productivity and creativity. It also can reduce the chance of staff burnout and turnover. Building interpersonal relationships and a culture of innovation and fun over the past several years has brought the staff at McIntyre Library on the University of Wisconsin-Eau Claire campus together and created a more cohesive working environment. Through various activities sponsored by the library, and activities that individuals have taken upon themselves to organize outside of the work day, the library is now a staff that more fully appreciates collaboration, innovation, and communication.

\section{Literature Review}


While there is substantial library literature on staff development, morale, and training, very few articles provide examples or cases where simple, inexpensive staff activities and events are successfully employed to address issues of staff divisiveness. A search of the database Library, Information Science \& Technology Abstracts (LISTA) yielded few results, with the emphasis on larger scale staff development events. Anecdotal, non-scholarly articles focused more on guidelines to follow for initiating staff development activities, such as planning events, projecting positive attitudes, and communicating. ${ }^{1}$ Everett discusses the various ways in which fun at work "is an outgrowth of a positive organizational culture," and the concept of fun at work can improve organizational goals while also improving the employee's job satisfaction and commitment. ${ }^{2}$ Themes of staff recruitment and retention, collegiality, improved customer service, and job satisfaction permeate the library literature. While there is some discussion of the discord between professional librarians and paraprofessionals or other staff members, very little is written about overcoming alleged, direct, or unintentional divisions among staff in different library departments or work areas.

Innumerable sources on the topic of staff morale and the concept of fun at work are found in the business, leadership, and management literature. Ford, McLaughlin and Newstrom found that human resource managers define fun at work as being "created through actions, including funny, humorous, or playful activities that publicly communicate management's belief to the employee that the personal and professional accomplishments he or she has achieved are valued by the organization." ${ }^{3}$ Many articles discuss specific workplace activities that large corporations use to recruit and retain employees. Google, for example, has been identified as one of the best examples of fun workplaces. In fact, in their "Top Ten 
Reasons to Work at Google," number four is "Work and play are not mutually exclusive." ${ }^{4}$ Google co-founder Larry Page maintains that “we don't just want you to have a great job. We want you to have a great life. We provide you with everything you need to be productive and happy on and off the clock. ${ }^{\prime \prime}$ While libraries certainly do not have the budgets and freedom that private companies like Google enjoy, there is literature that suggests that the concept of fun at work is the same for both public and private sectors. A study by Karl, Peluchette, Hall, and Harland compares attitudes toward workplace fun in public, nonprofit, and private sectors. ${ }^{6}$ Through the authors' extensive research it was clear that, while nonprofit and public establishments are different from private business in many respects, "all organizations are competing in a common labor market when it comes to recruiting and retaining employees." ${ }^{\prime 7}$

Other literature describes the rationale for why a fun work environment is important to companies' bottom lines. In Canadian Business, Wahl describes how companies that are consistently ranked as being "Great Place[s] to Work" outperform their peers in the stock market. ${ }^{8}$ A "great place to work" only exists if the employee trusts in the workplace itself. To have trust in their workplace, the workplace must have: credibility, respect, fairness, pride, and camaraderie. $^{9}$ These themes are not limited to the private sector; libraries whose employees believe they are treated respectfully and fairly are passionate about what they do, take pride in themselves and their libraries, and develop positive relationships with coworkers.

According to a recent Randstad Work Watch Survey, American workers are happier at their jobs because of the friendships they develop with colleagues, with sixty-seven percent reporting that having friends at work makes their job more fun and enjoyable; fifty-five percent 
feel that these relationships make their job more worthwhile and satisfying. ${ }^{10}$ Riordan and Griffith explored the idea of workplace friendships more explicitly in which they theorized that "friendship opportunities would have a positive and indirect effect on organizational commitment." ${ }^{11}$ Their findings support this positive association. ${ }^{12}$

The literature also suggests that good communication is a key to workplace cohesiveness and staff morale. Social interaction, and thus communication, "fosters the development of common values and goals, and aids in the achievement of those goals." ${ }^{13} \mathrm{~A}$ survey of job satisfaction found that eighty-five percent of employees state that their morale drops sharply after just six months on the job, but simple recognition can curb this; employees repeated often, and with great feeling, how much they appreciate a compliment. ${ }^{14}$

The business and management literature is full of articles and studies about fun in the workplace, and all express the same basic comments from employees who have fun at work. Employees who are allowed to have fun on the job report that they are less anxious and depressed, are more satisfied with their jobs and with their lives in general, and are more convinced that other people have fun at work. They are also more creative in their work, better able to meet job demands, less likely to be absent or late to work, and more motivated by their work. ${ }^{15}$ The idea of having fun may not be prevalent in the library literature, but it can be successfully employed in an academic library if the library culture is ready and willing.

\section{Background}

As of January 1, 2012, McIntyre Library on the University of Wisconsin-Eau Claire campus had a staff of ten professional librarians, fifteen paraprofessional staff, and over sixty student 
employees. Since the staff is relatively small, cross-departmental collaboration is essential to a happy and productive workplace. McIntyre Library, however, is not unlike other libraries in that its history affects the present day library. As two relatively new librarians at UW-Eau Claire, the authors have learned how divisions in the library have affected the current work environment. McIntyre Library is also not unique in that it finds itself in a transition phase. In just the past five years there have been many retirements, a change in directorship, and other staff turnover due to relocations. Of the professional librarians employed at McIntyre Library, only two remain from the previous administration. Staff members include those fresh out of library school, those who had a few years of experience before coming to McIntyre Library, and some who have fifteen or more years of experience in other library sectors or in different professions. With the addition of so many new personnel in the library, there is a lot of energy to try new things. These new things have not always been cutting edge services; quite often they are ideas adapted from a previous workplace or something that was read in a journal or online. Nevertheless, by doing things differently, not being afraid to fail, and working together on these new endeavors, McIntyre Library has experienced a sea change in its culture and atmosphere.

Probably the most crucial element leading to the atmospheric change in the library-asworkplace was a change in library management. A new director was hired recently and he brought somewhat new (to the staff) and unconventional attitudes towards traditional librarianship and library services. Director John Pollitz believes that the role of a leader is to articulate a vision, hire talented people, provide resources, and get out of the way. By giving 
his staff members the latitude to try new things, the library has become more collaborative and has a fun atmosphere that permeates the building.

\section{Library Divisions}

It is safe to say that in most libraries there can be spoken or unspoken contention between different service areas. The old organizational model of libraries, "with its separate departments for public and technical services, and its hierarchical routes of communication" somewhat stifled social interaction between librarians. ${ }^{16}$ Communication may have been inefficient, and cataloging staff, for instance, may have wondered what reference librarians did because they so seldom had a chance to interact. With the advent of information technologies, the lines of responsibility have blurred. There is now the necessity of having to work together and discuss services in a very different way. While new librarians may have an easier time with this interdepartmental communication, there can be generational differences regarding services and philosophies.

A problem that exists at, but is not unique to, McIntyre Library is who gets the credit for making the library run smoothly. Those who work in the library know that a lot of work goes into making the library's catalog run efficiently. Similarly, having databases that consistently work well and a library collection that is current, relevant, and actively used are necessary for the library to function and keep our users happy. Unfortunately, the personnel responsible for this do not always get credit. The public service personnel in circulation and reference are the point of contact for the library's users and thus get the praise when things work well or a user finds that "perfect" source in the library catalog. Public services staff are also often also the 
personnel who hear user frustrations and recommendations. Technical services is rarely commended by users with accolades and appreciation, instead usually hearing from public services staff about the problems with library products and services. Technical services must be content with the "no news is good news" attitude - otherwise, the overwhelmingly uneven ratio of complaints to praise would take its toll on employee morale and job satisfaction.

According to Jankowska and Marshall, "technical service librarians, primarily catalogers, have been traditionally concerned with the product - the creation of a catalog to the library's collection - and public service librarians, primarily reference librarians, with service - guiding patrons to the information sources they need. ${ }^{\prime 17}$ But these should not be separate goals; instead they are two parts of one whole. There is often disagreement between what public services staff want from the library catalog and what catalogers are willing and able to do. Public services staff may be of the opinion that technical services staff are too rigid and adhere too much to arbitrary rules. They may even feel that technical services is not taking the needs of the patrons to heart. On the other hand, technical services staff may ascribe a disregard for structure, principles, and standards to public services staff, or a lack of knowledge of the capabilities of library systems.

\section{Bridging the Great Divide}

So how to rectify the problems inherent in the division between public and technical services? Communication is the most important way to prevent the harboring of bad feelings. With positive communication, public services staff can learn the limitations of library systems and products, and technical services staff can come to appreciate the reasons why public services 
asks for alterations and improvements to library products and procedure. If there is generally good communication, then when conflicts arise, there are less likely to be problems because communication was of an ongoing nature. Librarians can benefit personally from such communication as well. Good communication between divisions and departments increases the development of peer and mentor relationships, possibly even friendships. ${ }^{18}$ At McIntyre Library, many cross-departmental relationships have led to collaborations on writing, presentations, and, projects within the library. These scholarly endeavors do not materialize without positive communication within the organization between individuals and departments.

In addition to a general understanding of each other's roles and interests in library service, showing appreciation for one another is an easy, non-threatening, and positive way to build relationships and rapport. Mclntyre Library has just finished a large weeding of the reference collection, having discarded or moved nearly three quarters of the materials. This was a time-intensive project that touched nearly every department in the library: the research and instruction librarians weeded the collection, cataloging staff handled the removal of large sets of materials from the catalog, collection development and electronic resources staff found ways to move several reference sets to e-book versions, and access services staff shifted books to make room for volumes the library kept in its circulating collection. Simple emails or words of thanks went a long way to show appreciation for making this seemingly easy project run smoothly. As was noted earlier, just as survey respondents in the corporate sector answered how much they appreciate compliments for their on the job performance, ${ }^{19}$ these results are just as applicable to academic libraries. Showing your gratitude for the work that someone else 
does makes them feel appreciated. Additionally, the successes you hear about should also be shared so that all staff involved are able to take credit for a job well done.

Building staff morale and cooperation between departments is more than just sending an email or stopping by someone's office to chat and acknowledge their work. It is also working together on teams and getting to know colleagues on a deeper level. Academic libraries are known for their formal and ad hoc committees, task forces, and working groups. While these obligations can serve as positive ways in which to collaborate and get to know each other, they rarely provide the opportunity to get to know your colleagues on a deeper, more personal level. At Mclntyre Library, we have an unofficial motto: "families who play together, stay together." And it is by "playing together" that we develop meaningful personal relationships that lead to a better understanding of our individual roles in the library.

What are some of the ways that libraries can play together? One easy way is literally to play together on a sports team. Mclntyre Library has a two such teams: a bowling team and an intramural ultimate frisbee team. The four-year old bowling team has been made up of members of various departments including members of the research \& instruction, systems, periodicals, and collection development departments. Each week during the bowling season, the team has a collective goal for each individual participant. As a reward for accomplishing that goal, team members go out for ice cream after bowling. That goal gets team members to root for each other but also builds a sense of "we're in this together" that makes participants want to learn more about each other. Undoubtedly, the bowlers learn about each other because of their participation in this game - their families, their aspirations, their personalities. 
They also learn about what others do at work because it is common for work issues to come up. These informal discussions lead to a better understanding of what each participant's role in the library is and how they fit into the big picture. In turn, when someone is critical of a viewpoint expressed at work, that criticism is not taken as personally because the individuals involved have gotten to know each other personally through their successes and failures as a team.

The library's intramural ultimate frisbee team is another form of play that participants from the library's circulation, research \& instruction, systems, and periodicals departments have joined. Unlike the library's bowling team, the library's ultimate frisbee team also has student participants from various departments within the library. As is the case with many academic libraries, the library could not function without its student workers. Libraries value their student workers, but it can be difficult to let them know how important they are. It is also important to make them feel that they are part of the library team. We have found that if students feel that they are more than just another cog in the machine, then the library staff becomes an extension of their university family. Getting to know staff and students in other departments because of their participation in an intramural team is an important step in building the morale of the students. At Mclntyre Library, the circulation and reference desk are located near, but not next to, each other. Because the circulation desk is the first service point seen upon entering the building, many users visiting the library ask questions there rather than at the reference desk. By getting to know students who work at the circulation desk via ultimate frisbee, many of the circulation desk students refer users to specific library staff or to the reference desk because they know someone personally who staffs the desk. As any marketer will tell you, word of mouth advertising is the best type of advertising. Furthermore, 
playing on a sports team humanizes the library staff for the student workers. They do not just see staff in the context of their day-to-day jobs, they also see them in the context of being a teammate and even a friend.

As with many libraries, we have found great success in simple events and activities held during the workday. Many of our internal activities are student-worker focused simply because they are our largest staff population. These events also provide an avenue for staff to work together across departments and levels to pull together a large social event.

One way in which our library builds the morale of its student workers is by hosting a student appreciation party at the end of the fall semester. Normally this takes place on a "study day" before finals when there are no classes held. The goal is to provide students with a home cooked meal and allow them to relax and interact with other students and staff. As part of the student appreciation party, library staff pitch in collectively to get every student a gift of appreciation for their work. Most of these gifts are snacks, gift cards to local coffee shops, and small things that students can use when studying for finals. During this party, the students graduating mid-year are specifically requested to attend for the "presentation of books." For the presentation of books, we ask graduating students to pick a book already in the library's collection, or choose one to be purchased for the collection. The library puts a bookplate in their honor in the front cover acknowledging their educational achievement and thanking them for all of the hard work that they have done for the library. In addition to the book plate, a picture of them is taken with their book and they are given a READ poster with that image. These are on display on the library's plasma screen monitors that are used for advertising. 
Though not as large as the appreciation party, the library also hosts a party for those graduating in the spring with cake, cookies, and punch. At that party the library also showcases graduating students through book selections and READ posters. Students generally comment on how they really appreciate what the library does to celebrate their work and express how much they will miss the library when they graduate.

Building student morale is more than just parties and sports; we also make a point to keep in touch with our students. Presently, that is easier with the advent of Facebook and Twitter, but another way is to get their contact information before they graduate. By getting their contact information, we are able to send out a copy of the biannual library newsletter to students via email. This is something that they are already familiar with since it is distributed to student workers in the library. The best part about this is that it is free. In addition to it being a way for the library to connect with students after graduation, we have found that this is a way to showcase our commitment to them after they have left the university. With such a kinship, we inevitably attract siblings and relatives of student workers to the library.

Though it may seem that a lot of the things that we have done at Mclntyre Library are student-focused, it is important to have specific events for permanent staff, too, because actively trying to make work fun leads to people having more fun on the job. ${ }^{20}$ One of the easiest ways to get people together is over food. The Karl, Peluchette, Hall, and Harland study found that the main activity all three sectors (public, nonprofit and private) viewed as the most enjoyable are those that are food-related. ${ }^{21}$ McIntyre Library has an annual soup luncheon in which staff members bring homemade soups for a staff potluck. This event is scheduled in 
January, between semesters, when the library is less busy and almost all of the staff members are able to attend. Another simple and cost-free option is to celebrate library-wide dress up days. It may seem a bit juvenile to have "dress up days," but a large portion of the library staff participates and often the general student body does as well. Halloween is by far the easiest and most recognized option, and at McIntyre Library, everyone from the library director to student workers participate. The library has also celebrated by having a Hawaiian shirt day, participating in "College Colors Day," and even "Talk Like a Pirate Day."

Formally planned events held outside of the library are more time consuming and take a great deal of preparation and dedication, but taking the time to organize such events demonstrates commitment to the library and colleagues. For five years, the authors of this chapter have organized an annual picnic and potluck at a local park after work. This event is held in either May, to celebrate the end of another successful academic year, or in August, to celebrate the start of another year of working together. Staff, their spouses, children, and significant others are all invited to attend. While waiting for the bratwurst and hotdogs on the grill, many people throw a Frisbee or football and children play on the jungle gym equipment; others converse about what is happening in their lives and get to know staff member's significant others. Due to budget constraints, the library is unable to furnish more than the cost of the park pavilion rental. The library staff association, to which we all contribute, donates twenty-five dollars, but there are usually no problems with staff contributing other funds to this event. 
In addition, due to all of the recent hires in the library, many new staff have hosted "open houses" outside of work hours. Staff members are under no obligation to host these after-hours get-togethers; individuals volunteer to do this as a way to get to know colleagues and their families better, but also as a way to show off a new apartment or house. As a relatively small staff, these events are good bonding experiences that bring people together over drinks, finger food, and games. In many cases, staff members bring their spouses, significant others, and children.

Finally, there is always happy hour. We have found that for many of the younger employees there is a need to decompress after a busy workweek. No one is under any obligation to attend happy hour, but there has been a good level of interest generated by these simple email invitations to meet at a local establishment after work. The number of attendees has also been surprising, as not only new librarians meet together, but long-timers, paraprofessional staff, and student workers come as well. Like every other library employee, each of our workdays can be filled with stressful situations, important decisions, difficult meetings, and obligations that pop up without warning. An evening of karaoke is another activity that alleviates stress and brings library staff together. Perhaps there is nothing more intimidating, or hysterical, than singing in front of a group of strangers and coworkers. The conversations and laughter that take place at karaoke provide a great release. With many individuals feeling the need to imbibe before taking to the stage, people are a bit freer with conversations. Karaoke events are usually tied to someone's birthday or as a way to celebrate the close of a successful semester. Employees in a fun work environment often complain less about boredom, anxiety and stress, ${ }^{22}$ and karaoke has provided the staff with a perfect outlet to 
let down their guards, become freer to talk openly about life and work, and strengthen positive relationships.

\section{Conclusion}

The concept of incorporating and allowing fun in the workplace is a phenomenon that has been taking over the private sector for years. That same concept is slowly but surely making its way into the library sector as well. The levels of fun that can be woven into an organization are based on leadership, employee attitudes, and actions. Simple steps can be taken, like those mentioned in this chapter, that cost little to no money. However, there is no silver bullet that will work for every library. But, not being afraid to try something new is an important lesson because you will find out more about your colleagues and their interests through whatever methods you choose to employ. Library staff are no different from private sector workers in that they desire trust, respect, and positive relationships with colleagues. Incorporating fun activities and a sense of humor into the library can result in increased employee productivity, creativity, motivation and satisfaction. These improved qualities in turn lead to a better provision of library services from all departments and from all statuses within the library, whether a student worker or a library faculty member.

\section{Notes}

1. Dan Connole, "Building Staff Morale," Virginia Libraries 46, no. 4 (2000): 13-15, http://scholar.lib.vt.edu/ejournals/VALib/v46_n4/v46_n4.pdf.

2. April Everett, "Benefits and Challenges of Fun in the Workplace," Library Leadership \& Management 25, no. 1 (2011): 1. 
3. Robert C. Ford, Frank S. McLaughlin, and John W. Newstrom, "Questions and Answers about Fun at Work," Human Resource Planning 26, no. 4 (2003): 22-23.

4. Google, "Top 10 Reasons to Work at Google," accessed February 14, 2012, http://www.google.com/intl/en/jobs/lifeatgoogle/toptenreasons/.

5. Larry Page, "Hiring Process" accessed February 14, 2012, http://www.google.com/intl/en/jobs/joininggoogle/hiringprocess/index.html.

6. Katherine Karl et al., "Attitudes Toward Workplace Fun: A Three Sector Comparison," Journal of Leadership \& Organizational Studies 12, no. 2 (2005): 1-17.

7. Ibid., 2.

8. Andrew Wahl, "Best Workplaces," Canadian Business 79, no. 8 (2006): 64-66.

9. Ibid.

10. "New Randstad Work Survey Finds Lines Between Personal and Workplace Friendships," Randstad Corporation, last modified February 23, 2010, http://us.randstad.com/content/aboutrandstad/news-and-press-releases/pressreleases/2010/20100223002.xml.

11. Christine M. Riordan and Rodger W. Griffeth, "The Opportunity for Friendship in the Workplace: An Underexplored Construct," Journal of Business and Psychology 10, no. 2 (1995), 144.

12. Ibid., 150.

13. Maria Anna Jankowska and Linnea Marshall, "Why Social Interaction and Good Communication in Academic Libraries Matters," Reference Librarian 40, no. 83/84 (2003): 133.

14. David Sirota, Louis A. Mischkind and Michael I. Meltzer, "Stop Demotivating Your Employees!" Harvard Management Update (July 2008): 3-5.

15. David J. Abramis, "Finding the Fun at Work," Psychology Today 23, no. 2 (1989): 3638; Kathryn Hawkins, "Build a Better Workplace," Office Pro 71, no.6 (2011): 32-35; Robert C. Ford, Frank S. McLaughlin, and John W. Newstrom, "Having Fun at Work," Engineering Management 14, no. 2 (2004): 32-33; Katherine Karl and Joy Peluchette, "How Does Workplace Fun Impact Employee Perceptions of Customer Service Quality?" Journal of Leadership \& Organizational Studies 13, no. 2 (2006): 2-13; John W. Newstrom, "Making Work Fun: An Important Role for Managers," SAM Advanced Management Journal 67, no. 1 (2002): 4-8, 21; Katherine M. Hudson, "Transforming a Conservative Company - One Laugh at a Time," Harvard Business Review 79, no. 7 (2001) 45-53; Mildred Golden Pryor et al. "Workplace Fun and its Correlates: A Conceptual Inquiry," International Journal of Management 27, no. 2 (2010): 294-302.

16. Jankowska and Marshall, "Why Social Interaction and Good Communication in Academic Libraries," 142.

17. Ibid., 135.

18. Ibid., 139.

19. Sirota et al., "Stop Demotivating Your Employees!" 3-5.

20. Abramis, "Finding Fun at Work," 36.

21. Karl et al., "Attitudes Toward Workplace Fun," 11.

22. Ford, McLaughlin, and Newstrom, "Questions and Answers about Fun at Work," 25. 